\title{
NUMERICAL SIMULATION OF HEAT TRANSFER BEHAVIOR OF DISSIMILAR AA5052-AA6061 PLATES IN FICTION STIR WELDING: AN EXPERIMENTAL VALIDATION
}

\author{
VISHWANATH M. M. ${ }^{1}$, LAKSHAMANASWAMY N. ${ }^{2}$, RAMESH G. K. ${ }^{3}$ \\ ${ }^{1}$ Department of Mechanical Engineering Dr. Ambedkar Institute of Technology, Bangalore, INDIA \\ ${ }^{2}$ Department of Mechanical Engineering University Visvesvaraya College of Engineering, Bangalore, INDIA. \\ ${ }^{3}$ Department of Mathematics, K.L.E Society's J.T. College, Gadag-582102, Karnataka, INDIA, \\ e-mail: gkrmaths@gmail.com
}

\begin{abstract}
Fiction Stir welding (FSW) a unique type of metal joining process in solid state, where the heat generation takes place due to the friction action between the rotating tool and the work piece. It is generally used to join all series of Aluminum alloys with good strength and other metallic alloys finds difficult to weld through regular fusion welding techniques. The metal joining takes place in the solid state as the metal to be welded reaches about $80 \%$ to $90 \%$ of its melting temperature. The joining of metals in friction stir welding does not require any filler metals all classes of Aluminium alloys can be joined and in some desirable cases dissimilar metal compositions and Aluminiun metals composites can be joined satisfactorily. Joining of dissimilar metals has become a trend in the industries like aerospace, automotive chemical etc. as the helps in reducing the cost incurred by eliminating the costly materials. In the present study an experimental investigations are made to study the heat transfer behavior by determining the temperature distribution in AA5052-AA6061 plates during the Friction Stir welding. A three dimensional transient analysis is made by using ANSYS finite element analysis software. Thermocouples are placed at the suitable locations and the same point the temperature readings were taken from the simulation results. The experimental data is compared with the numerically simulated results. The numerical simulations results obtained are in better agreement with the experimental data obtained.
\end{abstract}

KEYWORDS: Friction Stir Welding, Dissimilar metals, Aluminum alloy series, Heat source model, Transient analysis.

\section{Introduction}

The art of friction stir welding was first developed in 1991 by The Welding Institute (T W I), Great Abington, Cambridge of United Kingdom and is considered as the solid state metal joining technique initially applied for joining of aluminium plates. The friction Stir Welding unlike other fusion welding technique does not use any filler metals, cover gasses or flux and consumes very energy. The FSW is considered as the Green technology in welding as the process is environmental friendly without producing smoke. The friction stir welding is made by creating the heat caused by friction therefore, it consists of a rotating tool designed with shoulder and a pin arrangement made to rotate on the surface of the work piece to create friction and is traversed in the direction of weld to for a joint. The joining of metals does not require any filler metals and all the classes of the aluminium alloy series starting from 1xxx to 7xxx alloys, as well as the newer Al-Li alloys can be joined with different compositions and in some desirable cases the dissimilar aluminium alloys and the aluminium metal composites can be joined satisfactorily. In addition the Friction Stir welding has metallurgical and dimensional benefits like solid state joining, lesser distortion of work pieces, better geometrical stability, better metallurgical properties, absence of cracking, environmental benefits like absence of shielding gases that produces smoke, no grinding wastes and solvents 
requirements, consumable material savings and Energy benefits like require very less energy, less material usage, less fuel usage due to reduction in weight.

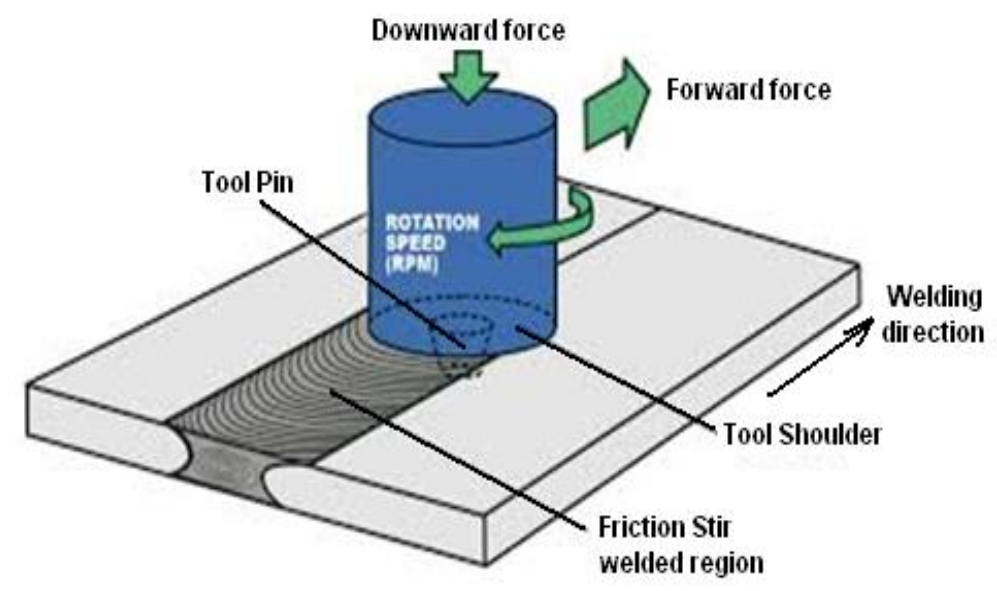

Fig. 1 Friction Stir Welding Process

The heat transfer studies in FSW plays a vital role in determining the quality of the weld. Research are made and many investigations are under progress in experimental and Numerical or FEM analysis of the Thermo - Mechanical behavior in the FSW of Aluminium alloy series with similar and dissimilar composition. McClure et al. [1] and Tang et al. [2] carried an experiment to measure the temperature distribution behavior in FSW to study heat transfer behavior in the work piece. Gould and Feng [3].developed a heat source model to investigate temperature distribution in the work piece. In this study it was considered that heat is generated at the tool shoulder only then observed how the generated heat is conducted to the plate. Chao and Qi $[4,5]$ made an experimental study to understand the temperature distribution and developed a moving heat source model by using FEA for validating the temperature curves with the experimental and evaluated the residual stress and distortion present in FSW. In this study the heat transfer in both tool and work piece were taken into account. Very recently Song and Kovacevic [6] investigated on a heat source model moving in a $3 \mathrm{D}$ co-ordinate system by adapting FEM technique to minimize the risk in modeling of the rotating tool in movement while welding in friction stir welding. Nandan et al.[7] developed a three dimensional model to study the plastic flow behavior in materials, the temperature distributed regions for experimental validations. Qasim M Doos et al.[8] made a numerical study by developing two different transient thermal and fluid thermal models. the results concludes that the results of transient thermal model was better than the fluid thermal model. Rajamanickam et al. [9] made a investigation on the thermal behavior of aluminium alloys in FSW by developing thermo-mechanical numerical model using FEM technique and suggested that the thermal models are very useful in obtaining the temperature data in the vicinity of tool shoulder. Hani et al. [10] made extensive investigations on FSW of copper alloys. In this study the different for the tool is used and the same is developed in the numerical model. The numerical simulation is carried and the results obtained are more reasonable with the experimental work carried. Hamed Pashazadeh et.al.[11] made the numerical investigation for the friction stir welding of copper. In this study a numerical models were developed to understand the thermal behavior around the weld joint and observed that heat distribution is not similar on either side around the joint. The peak temperature is always observed behind the tool pin. Chen and Kovacevic [12] made a investigation to study the thermal and mechanical behavior of aluminum AA6061-T6 Alloy. 
In this study a three dimensional thermal model was developed and simulation is made by using commercial FEM code ANSYS. Some numerical simulation works have been done for testifying by some researchers [13-15].

The present investigation focus on the thermal behavior during the Friction stir welding of dissimilar Aluminium alloys AA5052-AA6061 plate. The experimental work is carried out for the selected combination of dissimilar Aluminium alloys plates with suitable arrangement for the temperature data with data acquisition and transferred to the computer and numerical simulation is carried out by FEA software ANSYS. Pavelic circular disc heat source model, Thermo - Mechanical properties Aluminium alloys AA5052-AA6061, convective boundary conditions are applied during the numerical simulation process. Finally the results obtained by the numerical simulation are examined with the simulation results.

\section{Experimental Investigations}

The experimental investigations are carried to obtain the temperature data's for the joining of dissimilar AA5052-AA6061 plates by friction stir welding. The following Fig 1. shows the friction stir welding of the AA5052-AA6061 plates with a conventional milling machine with suitable arrangements required for the Friction stir welding.

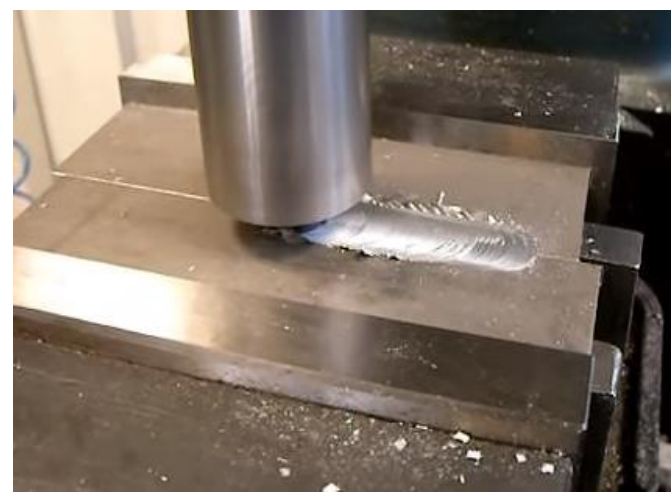

(a)

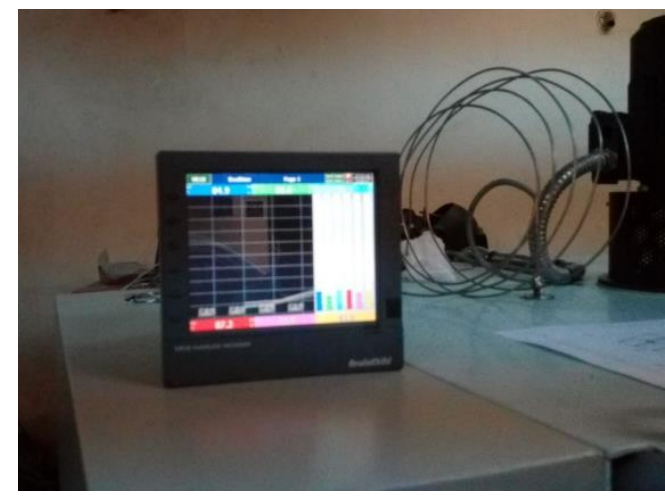

(b)

Fig. 2 a) Fiction Stir Welding of AA5052-AA6061 plates with a conventional milling machine. b) Temperature - time measurement with data acquisition.

The experiment is conducted for the friction stir welding of dissimilar combination of AA5052-AA6061 plate samples having the dimension $300 \mathrm{~mm}$ length, $150 \mathrm{~mm}$ width and $6.35 \mathrm{~mm}$ thickness. The fiction stir welding is carried out for the rotational speed of tool between 1100rpm and the traversed speed of $360 \mathrm{~mm} / \mathrm{min}$. the tool is of two sided straight pin type FSW tool made up of Tungsten carbide - 10\% Cobalt. The tool has the outer diameter of $25 \mathrm{~mm}$, length $60 \mathrm{~mm}$ and the pin is of $10 \mathrm{~mm}$ outer diameter and $5 \mathrm{~mm}$ height. Suitable clamping arrangements are made to hold the work piece. Both the end clamping and the bottom supports are made to hold the plates firmly. Due to the friction between tool and the plate there will an intense plastic deformation of the metal in and around the rotating tool therefore placing the thermocouple is very important to obtain the temperature distribution.

Four K- type thermocouples $3 \mathrm{~mm}$ Mineral Insulated $2 \mathrm{mtr}$, long with quick detachable connector, Tip foxing bolt type, bolt $6 \mathrm{~mm} \times 15 \mathrm{~mm}$ are pinned from the bottom of the plate where the temperature can be measure up to $1000^{\circ} \mathrm{C}$ at the distance of $12 \mathrm{~mm}$ and $16 \mathrm{~mm}$ on either side of the plates from the weld centre the locations of the thermocouple is as shown in the Fig 4. TC1, TC2, TC3 and TC4 represent the thermocouples locations. The temperature output data is obtained by the Temperature Recorder 'Brain Child' make PR series - 6 Chanel 
of 4.5" TFT touch screen with data acquisition where the temperatures are recorded with respect to time and the experimentally recorded data are then transferred to the computer and necessary graphs are plotted.
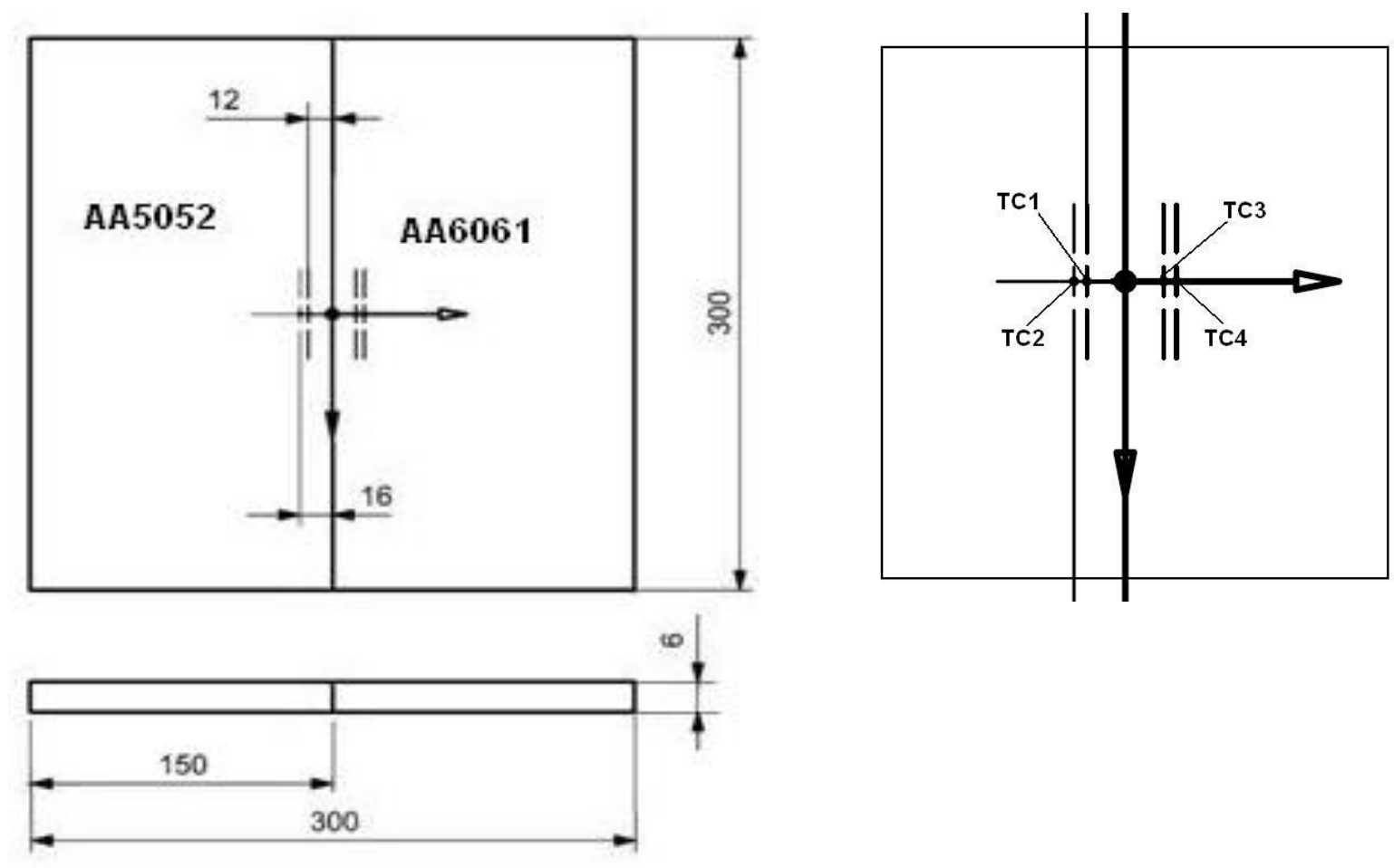

Fig. 3 Model dimension and thermocouple location.

\section{$3 \quad$ Numerical Modeling and FEA Simulation using ANSYS}

A three dimensional numerical models are developed and mesing as been made, but in order to simulate the process, circular disc eat source model proposed by Pavelic is applied on the face where the tool shoulder and work piece in contact for friction with the moving heat source in the Finite element analysis software ANSYS. The temperature distribution in the friction stir welding of dissimilar AA5052-AA6061 plates is analyzed. The temperature distribution curves obtained in the numerical simulation is compared with temperature data obtained from the experimental investigation to validate the simulation process. The following flow chart shows the brief details of numerical simulation performed.

\subsection{Temperature Dependent Material Properties:}

The transient temperature distribution is a function of time and the coordinates system in the weld plates. The heat balance equation consists of Temperature dependent thermal properties like density, specific heat, thermal conductivity etc. These material properties generally dependent on the temperature and is important for the heat transfer studies in welding. ANSYS software package allows researchers to define its temperature dependent properties for the materials been modeled to carrying out the simulation process. The thermal properties of the materials AA5052 and AA6061 aluminium alloys used in the present numerical simulation are tabulated in Table 1 and Table 2. As the FSW is solid state welding process thermal properties in the liquid region are not taken into consideration. 


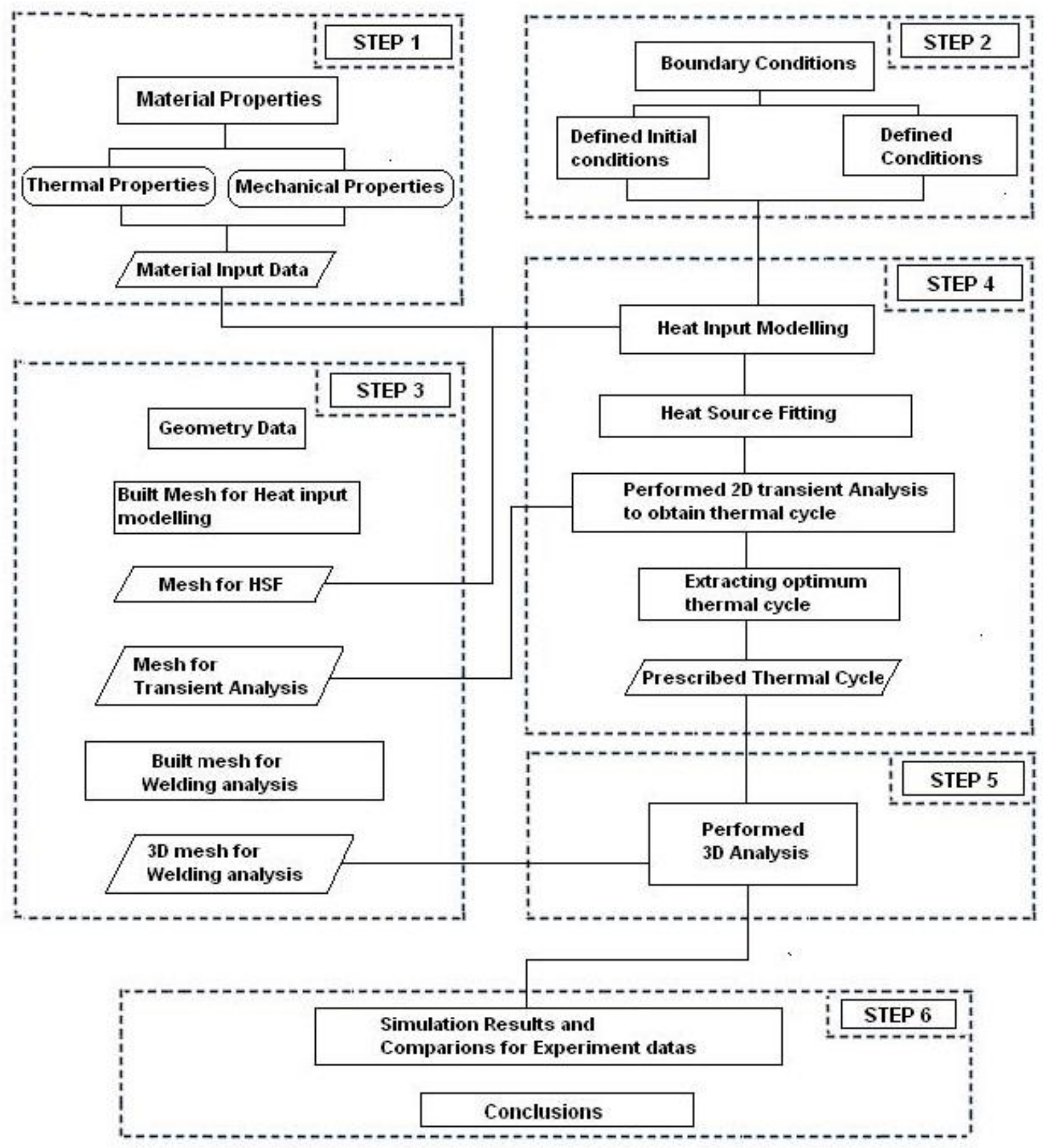

Fig. 4 Flow chart for the numerical simulation of FSW

\subsection{Geometrical modeling and Meshing:}

The 3D Modeling and Meshing required for simulating the welding process with 3D moving heat source is represented in the Fig 4 and Fig 5. 3D modeling is made for both for work piece and the tool touching the disc face of tool at the surface of the work piece and positioned such that the tool can move during the simulation as identical to the experimental welding. The meshing is made in the meshing available in the ANSYS workbench with 212859 nodes and 129051 elements which help in location the position of the thermocouple at the node and to study the temperature distributions on that location. The dimensions are maintained for the tool and work piece used experimentally. 
Table 1: Temperature dependent material properties of AA5052

\begin{tabular}{lllll}
$\begin{array}{l}\text { Temperature } \\
(\circ \mathbf{C})\end{array}$ & $\begin{array}{l}\text { Density } \\
(\mathbf{K g} / \mathbf{m 3})\end{array}$ & $\begin{array}{l}\text { Specific heat } \\
(\mathrm{KJ} / \mathbf{k g} \circ \mathbf{C})\end{array}$ & $\begin{array}{l}\text { Thermal } \\
\text { conductivity } \\
\left(\mathbf{W} / \mathbf{m}^{\circ} \mathbf{C}\right)\end{array}$ & $\begin{array}{l}\text { Enthalpy } \\
(\mathbf{G J} / \mathbf{m 3})\end{array}$ \\
\hline 10 & 2781.25 & 0.9 & 162.5 & 0.025 \\
80 & 2756.25 & 0.98 & 168.75 & 0.200 \\
180 & 2695 & 1.07 & 193.75 & 0.467 \\
280 & 2650.5 & 1.1 & 206.25 & 0.819 \\
380 & 2610.66 & 1.15 & 225 & 1.118 \\
480 & 2605 & 1.2 & 237.5 & 1.466 \\
\hline
\end{tabular}

Table 2: Temperature dependent material properties of AA6061

\begin{tabular}{lllll}
\hline $\begin{array}{l}\text { Temperature } \\
(\circ \mathbf{C})\end{array}$ & $\begin{array}{l}\text { Density } \\
(\mathbf{K g} / \mathbf{m} 3)\end{array}$ & $\begin{array}{l}\text { Specific heat } \\
(\mathbf{K J} / \mathbf{k g} \circ \mathbf{C})\end{array}$ & $\begin{array}{l}\text { Thermal } \\
\text { conductivity } \\
(\mathbf{W} / \mathbf{m} \circ \mathbf{C})\end{array}$ & $\begin{array}{l}\text { Enthalpy } \\
(\mathbf{G J} / \mathbf{m})\end{array}$ \\
\hline 25 & 2700 & 0.896 & 167 & 0.060 \\
37.8 & 2685 & 0.92 & 170 & 0.091 \\
93.3 & 2685 & 0.978 & 170 & 0.229 \\
148.9 & 2667 & 1.004 & 184 & 0.385 \\
204.4 & 2657 & 1.028 & 192 & 0.540 \\
260 & 2657 & 1.052 & 201 & 0.702 \\
315.6 & 2630 & 1.078 & 207 & 0.872 \\
371.1 & 2620 & 1.104 & 217 & 1.041 \\
426.7 & 2602 & 1.133 & 223 & 1.222 \\
\hline
\end{tabular}

\subsection{Heat Source Modeling}

Circular disc' model in 1965 was proposed by Pavelic et a1.[3] is more realistic as compared to the point heat source and line heat source developed by Rosenthal, as it distributes the heat input over a source area. These models were most commonly applicable in the solid state welding processes like friction stir welding, where the temperature is $15-20 \%$ less than the melting temperature of the welded joints. This model give accurate results in the arc welding with the better heat distribution in the molten Heat affected zones.

The fig 6 shows the heat distribution on a circular disc model presented by the Pavelic. This circular disc model is more realistic and practical as compared to point and line heat source models because the heat distribution takes place over a source surface area. This disc model also allows the convective and radiation boundary conditions for the better heat distribution. 


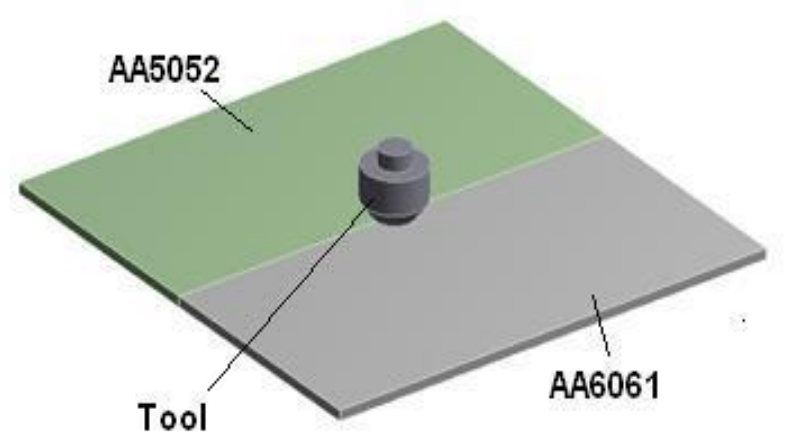

Fig. 5 3D modeling of the tool and work piece.

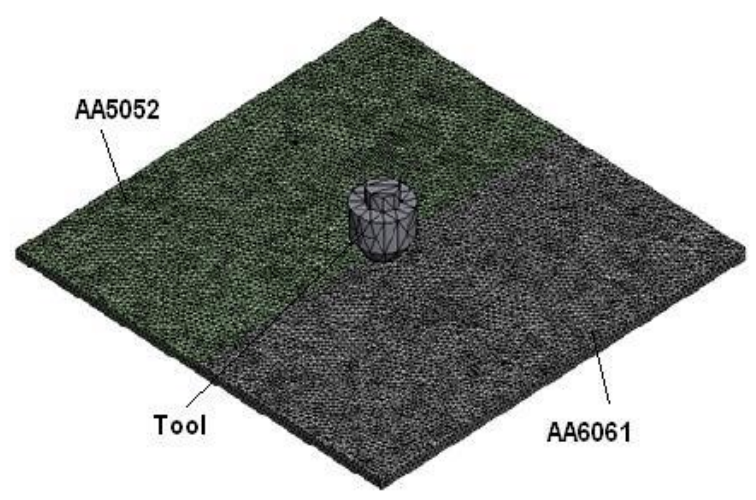

Fig. 6 Finite Element meshing of the tool and work piece

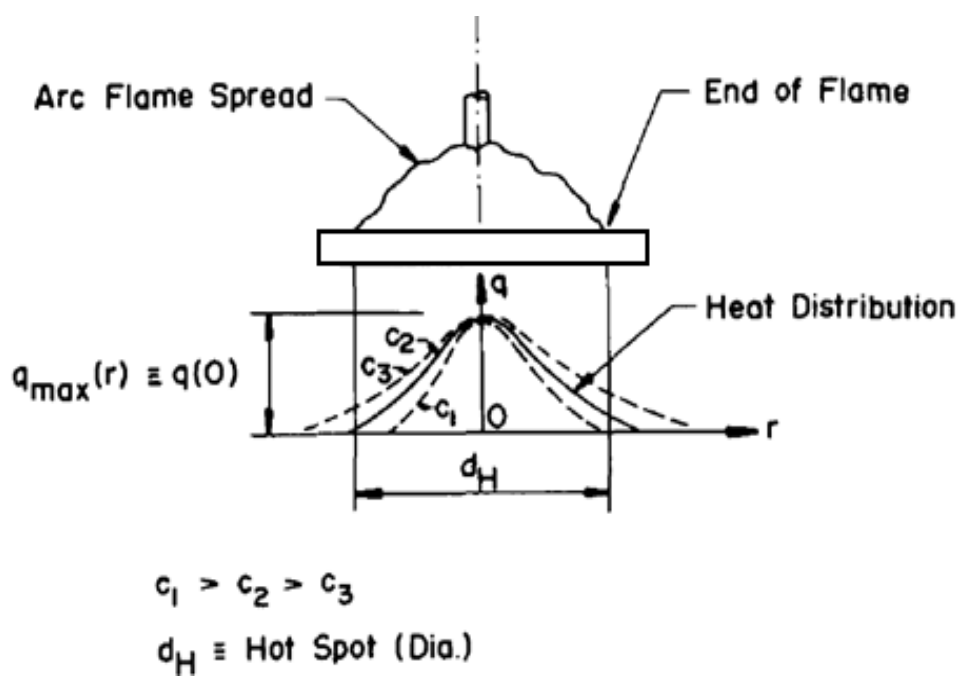

Fig. 7 Pavelic's Circular disc heat source model

The surface heat flux at any radius $r$ is given by,

$$
q_{r}=q_{0} e^{-C r^{2}} \mathrm{~W} / \mathrm{m}^{2}
$$

where $q_{r}$ is the heat flux at the contact of tool shoulder and working plates at a distance of radius ' $r$ ' in $\mathrm{W} / \mathrm{m}^{2}, q_{0}$ is the maximum heat flux obtained at the centre $\left(\mathrm{W} / \mathrm{m}^{2}\right), C$ is the distribution coefficient in $\mathrm{m}^{-2}$. 


\subsection{FEA simulation using ANSYS.}

For simulating the Friction Stir welding process with surface circular disc model moving heat source, ANSYS Workbench 15.0 software has been used. The present simulation only focuses on thermal behavior during the Friction stir welding of dissimilar AA5052-AA6061 plates. For performing the simulation, transient thermal analysis was carried in order to simulate the temperature distribution curves.

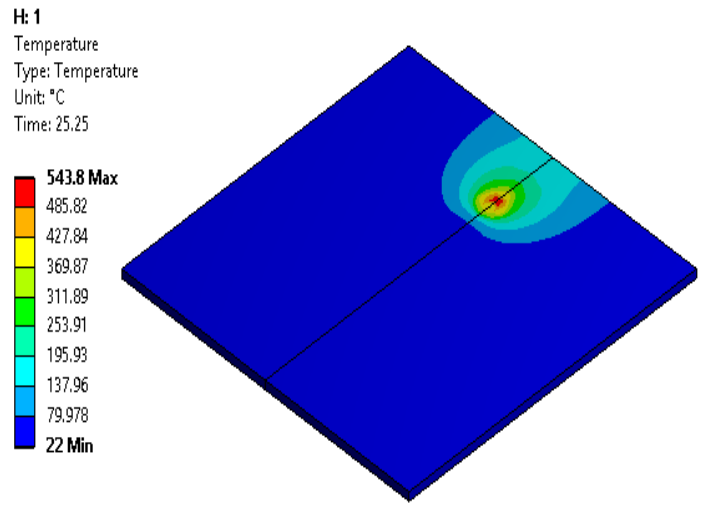

(a)
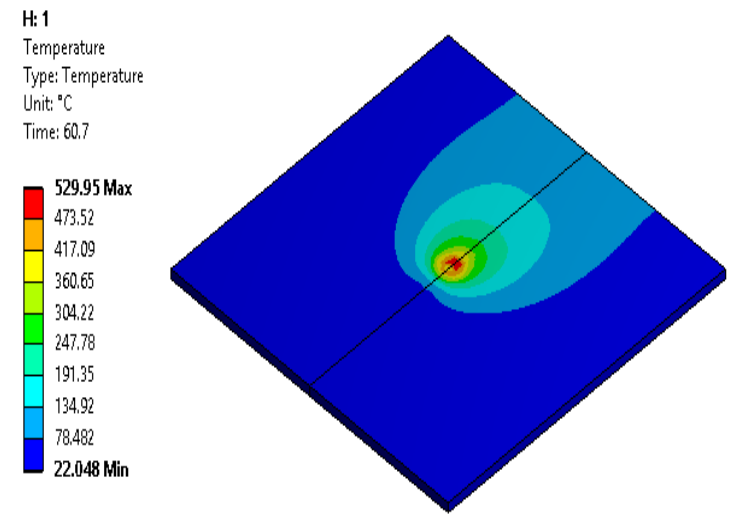

(c)

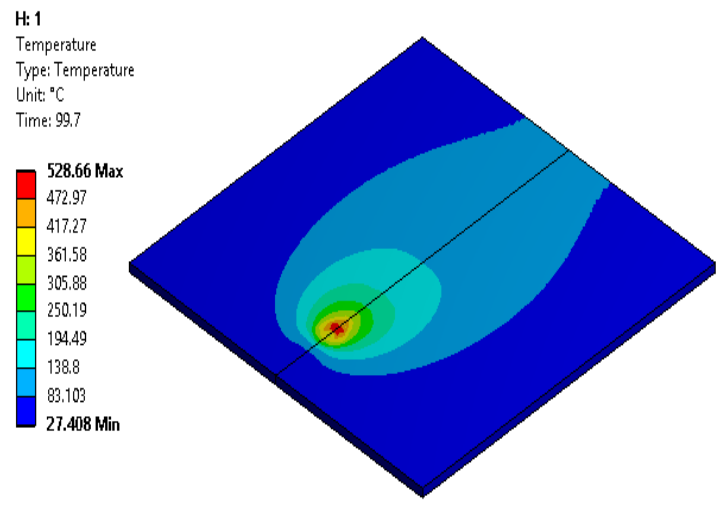

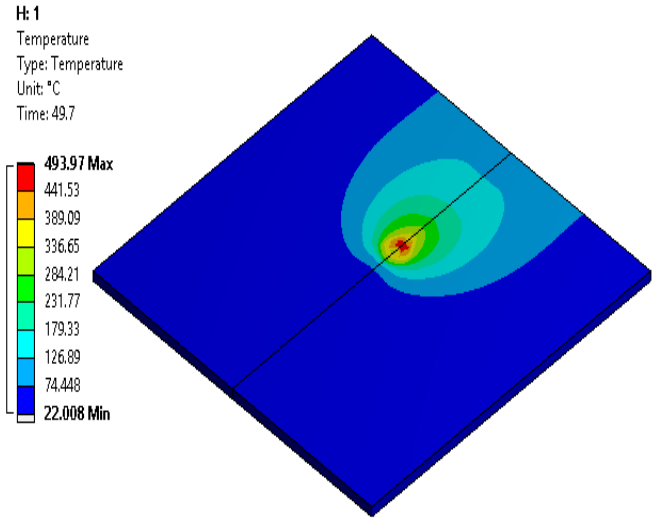

(b)
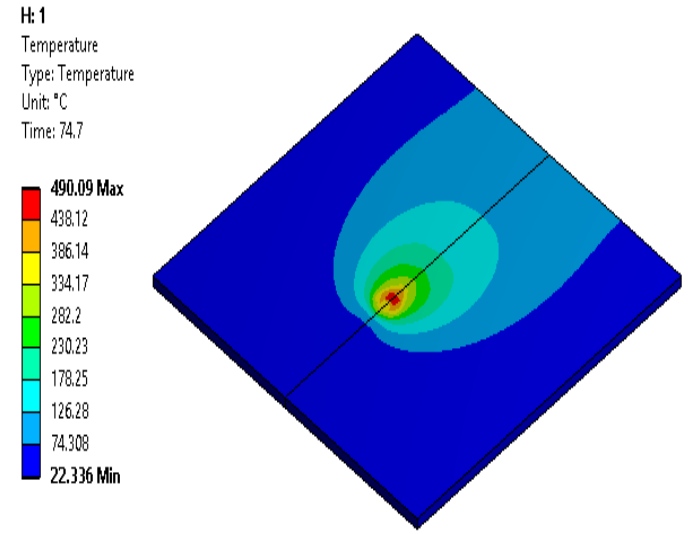

(d)

(e)

Fig. 8 Numerically simulated temperature contours in dissimilar aluminium alloy AA5052AA6061 plates at time steps (a) 30s (b) 60s (c) 90s (d) 120s and e) 150s during FSW welding. 
The above figure represents numerically simulated temperature contours in dissimilar aluminium alloy AA5052-AA6061 plates at time steps (a) 30s (b) 60s (c) 90s (d) 120s and d) 120 s during FSW welding using ANSYS workbench 18. The peak temperature attained during the process is $543.8^{\circ} \mathrm{C}$ at the beginning 30 seconds and the maximum temperature of $493.57^{\circ} \mathrm{C}, 529.95^{\circ} \mathrm{C}, 490.09^{\circ} \mathrm{C}, 528.66^{\circ} \mathrm{C}$ were observed during next $60,90,120$ and 150 seconds respectively. The above peak temperature indicates the plastic formation of the metal before the melting point require for friction stir welding. The peak temperature attained almost at the middle near the tool pin and distributed gradually as the circular disc moving from one end to the other end. The minimum temperature of $74^{\circ} \mathrm{C}$ to $79^{\circ} \mathrm{C}$ is present till the welding ends.

\section{$4 \quad$ Results and Discussions}

The Temperature -Time curves during the transient heat transfer in the AA5052 and AA6061 plates of Friction stir welding were extracted by the temperature output data is obtained by the Temperature Recorder 'Brain Child' make PR series - 6 Chanel of 4.5" TFT touch screen with data acquisition by placing the K-Type thermocouples at $12 \mathrm{~mm}$ and $16 \mathrm{~mm}$ from the welding line in order to validate the numerical simulation results carried in ANSYS workbench. A peak temperature was recorded in temperature recorder as the welding tool reaches the thermocouple and as the tool departs from the centre the heat dissipation takes place by conduction and convection. Fig. 9 and Fig. 10 shows the Temperature -Time curves experimental and numerical simulation data obtained from the investigation.

Temperature distribution curves plotted shows a similar nature of curves exists in experimental temperature data and numerical simulation temperature data. There is a very small deviation in the numerical simulation results because of thermal inertia of measuring device and heat transfer coefficient of the air with respect to temperature is not considered only a standard value of $30 \mathrm{~W} / \mathrm{m} 2$ of heat transfer coefficient is considered in the study as per the survey. from the Fig. 9 and Fig. 10. The peak temperature in the numerical simulation of AA5052 plate is $341^{\circ} \mathrm{C}$ at 62 second at the centre of the plate for the thermocouple placed at $12 \mathrm{~mm}$ distance from the weld centre and $293^{\circ} \mathrm{C}$ at 66 second for the thermocouple placed at $16 \mathrm{~mm}$ distance. There is about 4 second difference in obtaining the peak temperature due to the conduction lag occurred by thermocouple mounting. The peak temperature in the numerical simulation of AA6061 plate is $339^{\circ} \mathrm{C}$ at 62 second at the centre of the plate for the thermocouple placed at $12 \mathrm{~mm}$ distance from the weld centre and $291^{\circ} \mathrm{C}$ at 66 second for the thermocouple placed at $16 \mathrm{~mm}$ distance. There is about 4 second difference in obtaining the peak temperature due to the conduction lag occurred by thermocouple mounting. Similar nature of curve is obtained in experimental observations. 

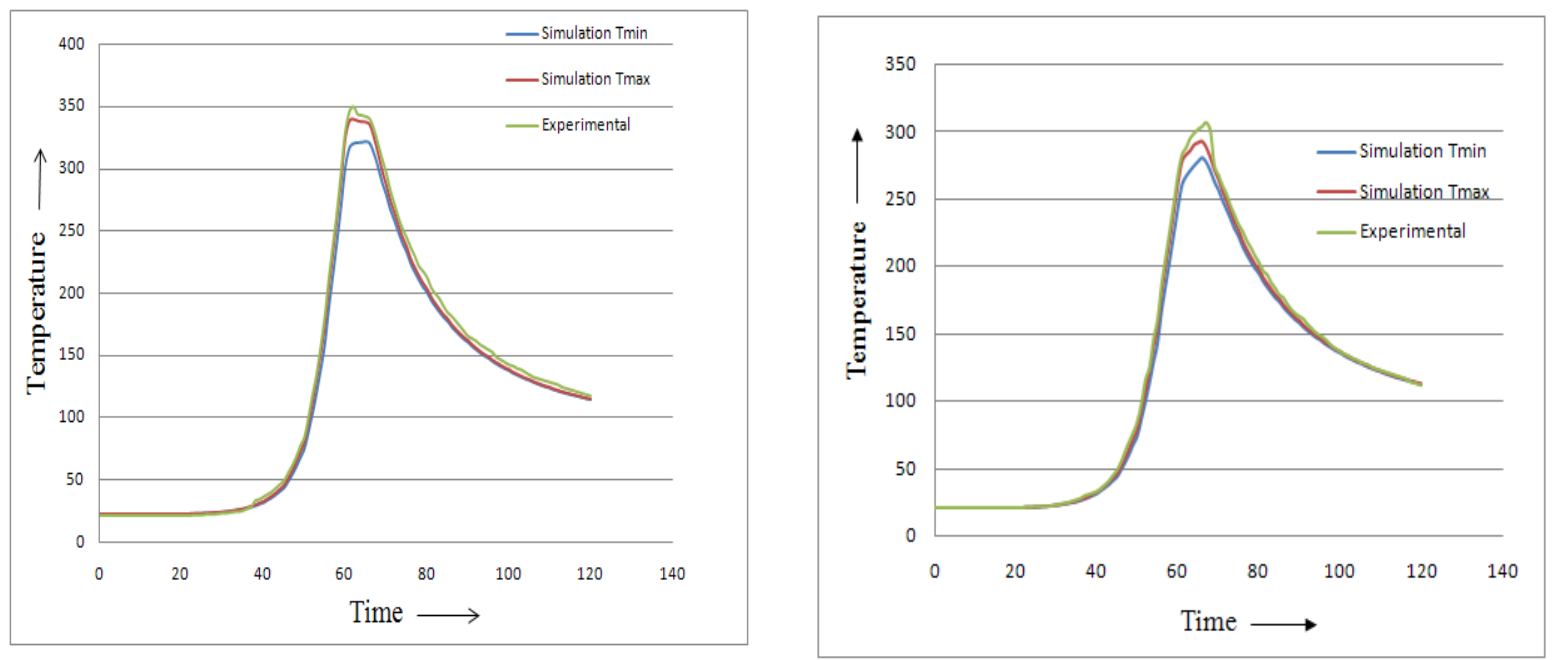

Fig. 9 Comparison between Experimental and Numerically simulated Temperature - Time curves for AA5052 plate at a distance of $12 \mathrm{~mm}$ (left) and $16 \mathrm{~mm}$ (right) from weld centre line.
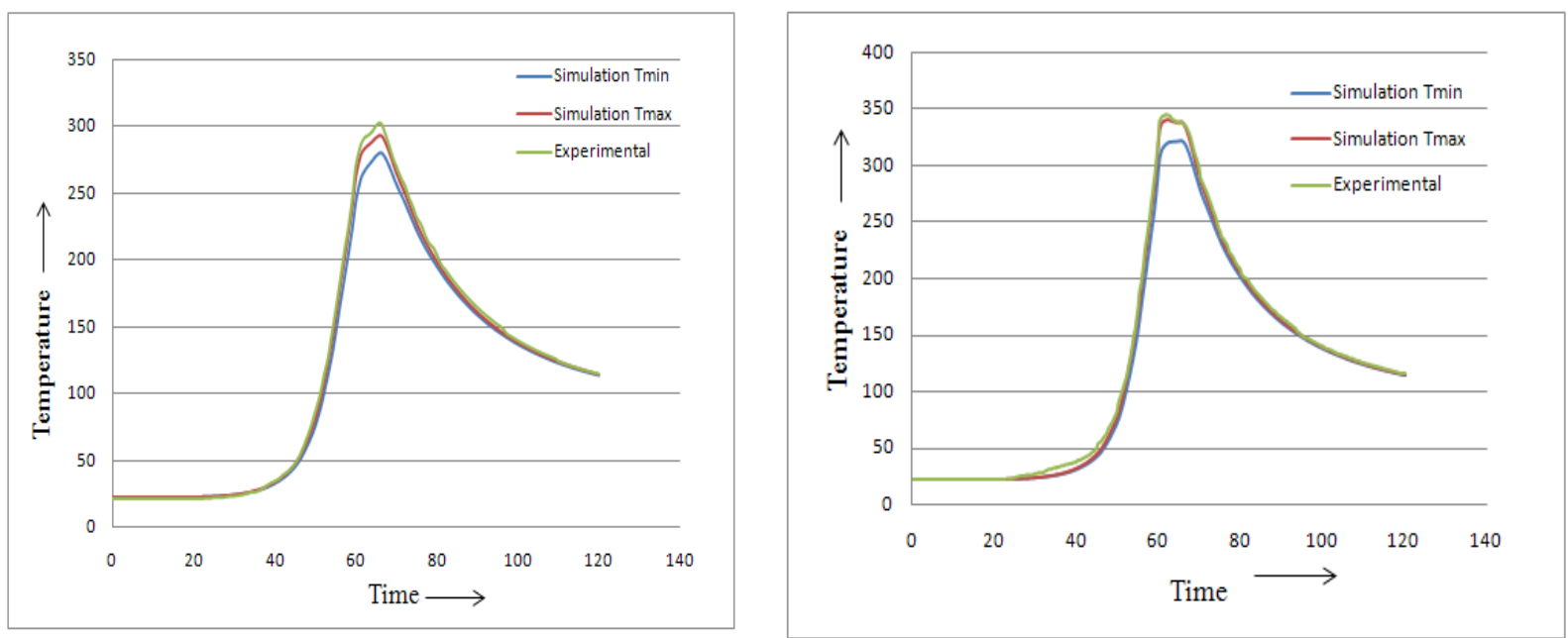

Fig. 10 Comparison between Experimental and Numerically simulated Temperature - Time curves for AA6061 plate at a distance of $12 \mathrm{~mm}$ (left) and 16mm (right) from weld centre line.

\section{CONCLUSION}

The experiment is conducted for the friction stir welding of dissimilar combination of AA5052-AA6061 plate samples having the dimension $300 \mathrm{~mm}$ length, $150 \mathrm{~mm}$ width and $6.35 \mathrm{~mm}$ thickness temperature data obtained as discussed in the previous session and numerical simulation were carried with surface circular disc model moving heat source, ANSYS Workbench 15.0 software has been used. The experimental data is compared with the numerically simulated results and draws the following conclusions:

1. The heat distribution are similar in both AA5052 and AA6061 Aluminium alloys as indicated by the indicated in the temperature contours due to the nearest thermal properties of both metals.

2. The nature temperature curve obtained in the experimental is identical with the numerical simulation curve indicating the right choice of the Pavelic's Circular disc heat source model.

3. The temperature curve indicate the occurrence of Friction stir welding in the plastic state and the maximum value temperature attained in the simulation is well agreement 
with the Experimental data indicating the validated simulation study of heat transfer behavior of the friction stir welding process.

\section{REFERENCES}

[1] McClure, J. C., Tang, T., Murr, L. E., Guo, X., Feng, Z. "A Thermal Model of Friction Stir Welding", Trends in Welding Research, J. M. Vitek, et al., eds., Proceedings of the 5th International Conference, Pine Mountain, GA, June 1-5, pp. 590 - 595. 1998.

[2] Tang, W., Guo, X., McClure, J. C., Murr, L. E., Nunes, A. "Heat Input and Temperature Distribution in Friction Stir Welding", Journal of Materials Processing and Manufacturing Science 7 2!, pp. 163 - 172, 1988. DOI: 10.1106/55TF-PF2G-JBH21Q2B

[3] Gould, J., Feng, Z. "Heat Flow Model for Friction Stir Welding of Aluminum Alloys", Journal of Materials Processing \& Manufacturing Science 7 2!, pp. 185 - 194, 1998. DOI: 10.1106/648R-2CNE-2PD0-45L6

[4] Chao, Y. J., Qi, X. "Heat Transfer and Thermo-Mechanical Analysis of Friction Stir Joining of AA6061-T6 Plates", Proceedings of the First International Symposium on Friction Stir Welding, June 14-16, 1999, Rockwell Science Center, Thousand Oaks, California, 1999.

[5] Chao, Y. J., Qi, X., Tang, W. "Heat Transfer in Friction Stir Welding - Experimental and Numerical Studies", Journal of Manufacturing Science and Engineering 125, pp. 138 - 145, 2003. DOI: $10.1115 / 1.1537741$

[6] Song, M., Kovacevic, R. "Thermal modeling of friction stir welding in a moving coordinate system and its validation", International Journal of Machine Tools and Manufacture 43, pp. 605 - 615, 2003. DOI: 10.1016/S0890-6955(03)00022-1

[7] Nandan, R., Roy, G.G., Debroy, T. "Numerical simulation of 3D heat transfer and plastic flow during friction stir welding", Metallurgical and materials transactions A. 37a, 1247 - 1259, 2006. DOI: 10.1179/174329306X107692

[8] Qasim M. Doos., Muhsin, J. J., Sarmad, D. R. "Analysis of friction stir welds. Part I: Transient thermal simulation using moving heat source", First Regional Conference of Eng. Sci. NUCEJ Spatial issue 11(3), pp. 429-437, 2008.

[9] Rajamanickam, N., Balusamy, V., Thyla, P. R., Vignesh, G. H. "Numerical simulation of thermal history and residual stresses in friction stirwelding of Al 2014-T6", Journal of Scientific and Industrial Research 68, pp. 192 - 198, 2009.

[10] Ameen, H. A., Abood, A. H. and Thamer, N. S., "Theoretical and experimental investigation of friction stir welding for copper alloy, AL-Qadisiya", Journal For Engineering Sciences 6 (3), pp. 332 - 351, 2013.

[11] Pashazadeh, H., Teimournezhad, J., Masoumi, A. "Numerical investigation on the mechanical, thermal, metallurgical andmaterial flow characteristics in friction stir welding of copper sheets with experimental verification”, Materials \& Design 55, pp. 619 - 632, 2014. DOI: 10.1016/j.matdes.2013.09.028

[12] Chen, C. M., Kovacevic, R. "Finite element modeling of friction stirs welding-thermal and thermo-mechanical analysis", Machine Tools \& Manufacture 43, pp. 1319 - 1326, 2003. DOI: $10.1016 / \mathrm{S} 0890-6955(03) 00158-5$ 
[13] Jančo, R., Écsi, L., Élesztős, P. "FSW Numerical simulation of aluminium plates by sysweld - Part I", Journal of Mechanical Engineering - Strojnícky časopis 66 (1), pp. 47 - 52, 2016. DOI: $10.1515 /$ scjme-2016-0010

[14] Jančo, R., Écsi, L., Élesztős, P. "FSW Numerical simulation of aluminium plates by sysweld - Part II", Journal of Mechanical Engineering - Strojnícky časopis 66 (2), pp. 29 - 36, 2016. DOI: $10.1515 /$ scjme-2016-0016

[15] Élesztős P., Jančo, R., Voštiar, V. “Optimization of welding process using a genetic algorithm”, Journal of Mechanical Engineering - Strojnícky časopis 68 (2), pp. 17 - 24, 2018. DOI: $10.2478 /$ scjme-2018-0014 